\title{
A Study of Some Quality Characteristics of Paracetamol Tablet
}

\author{
Oladimeji O. A. ${ }^{1} \quad$ Lasisi T. A. $^{2} \quad$ Apata O. T. ${ }^{3} \quad$ Ogunbanwo T. S. ${ }^{4}$ \\ 1.Department of Statistics, Federal Polytechnic, Ile-Oluji, Ondo State, Nigeria \\ 2.Department of Mathematics and Statistics, The Polytechnic, Ibadan, Oyo State, Nigeria \\ 3.Department of Mathematics, Federal College of Education, Okene Nigeria \\ 4.Department of Mathematics and Statistics, Osun State College of Technology, Esa-Oke, Osun State, Nigeria
}

\begin{abstract}
This paper is focused on the study of some quality characteristics of Paracetamol Tablet produced by TUYIL Pharmaceutical Industry Limited, Ilorin, Kwara State between January and June 2019. The data used was a secondary data collected from the quality department of the company, and collected on the following four quality characteristics: average weight (milligram), hardness (kilo pounds), disintegration time (minutes), and friability (percentage) as in the appendix. The Pattern of distribution was examined for the characteristics through their histogram and monitored using $\bar{X}$-chart and R-chart. The process capability analysis was carried out by estimating the capability indexes $\left(C_{p}\right.$ and $\left.C_{p k}\right)$. All the quality characteristics studied are in statistical control, capable of producing within their specified range. All the pairs of the quality characteristics are significantly correlated.

Keywords:Specification Limits, Upper Control Limit, Lower Control Limit, Statistical Process Control, Average Weight, Disintegration Time, Hardness, Friability

DOI: $10.7176 / \mathrm{JHMN} / 95-03$

Publication date: November $30^{\text {th }} 2021$

\section{INTRODUCTION}

Tuyil Pharmaceutical Industries Limited is a private owned business enterprises, it was established on the $1^{\text {st }}$ of May 1996 at No 22 Stadium Road Ilorin, Kwara state Nigeria. It is a Phamaceutical company that manufactures both human and veterinary products. Due to its rapid expansion in production activities, the company moved to its permanent site at No 22 New Yidi Road Ilorin, Kwara State Nigeria on the $2^{\text {nd }}$ of June, 2005 and was commissioned by the then Kwara State Governor Dr. BukolaSaraki and former Director General of NAFDAC, (Late) Prof Dora Akunyili as a special guest.

Tuyil Pharmaceutical Industries Limited is committed to the manufacture, distribution and delivery of quality health care products and services that constantly meet the needs of their esteemed customers. They are also committed to the proper implementation, maintenance and continual improvement of the effective quality management system standard and its requirement to improve the well-being of the nation.
\end{abstract}

\section{AIM AND OBJECTIVES OF THE STUDY}

This paper is aimed at studying the quality characteristics of Paracetamol (Tumol $\times 200)$ tablet produced by TUYIL PHARMACEUTICAL LIMITED and its objectives are:

- To determine the pattern of distribution

- To monitor the quality characteristics

- To obtain the process capability indices

- To examine the possible relationship between the pairs of quality characteristics.

This will be done for each quality characteristics.

The data used for this paper was extracted as a secondary data from the quality assurance department of Tuyil Pharmaceutical Limited, Ilorin, Kwara State on some quality characteristics of Paracetamol (Tumol $\times 200)$ tablet produced. The data was collected over theperiod of 6 months (Jan - Jun 2019) on four (4) quality characteristics i.e. Weight, Hardness, Disintegration Time and Friability.

\section{LITERATURE REVIEW}

Quality has become one of the most important customer decision factors in the selection among competing products and services. The phenomenon is widespread, regardless of whether the customer is an individual, an industrial organization, a retail store, a bank or financial institution, or a military defense program. Consequently, understanding and improving quality are the key factors leading to business success, growth, and enhanced competitiveness. There is a substantial return on investment from improved quality and from successfully employing quality as an integral part of overall business strategy.

All reputable pharmaceutical companies will surely agree that the quality control department of a drug manufacturing company is an essential, compulsory, indispensable and undeniable section of a pharmaceutical company, as it determines the acceptance or rejection of the company's product by the customers. It is also a 
vital segment of the health cycle as it helps in conducting research and manufacturing products which are life maintaining and life restoring. The products are critically essential for maintaining and sustaining the delivery to Nigerians an excellent health service.

The quality control department of any manufacturing company plays a key role in determining the quality of products been manufactured by a cooperation whether it complies with the laid down standards and that standard are met at all time.

Pharmaceutical companies maintain a reputation of working closely with Doctors, Teaching Hospitals, State and Federal Hospitals and Clinics as well as Private Hospitals to satisfy them with quality products (Drugs) for health care of people.

This reputation is maintained by assuring the safety and therapeutic efficacy of drug products which is a result of many factors which are either internal or external to the industry. Internally, are the self-designed guidelines and strict rules that the industry has imposed on themselves to guide and regulate their process, while externally are the control and inspection of manufacturing facility.

\section{Drug Specification as Part of Standard}

The major reason for having specifications of drugs in place is to ensure the specific drug dosage conforms to the required standard of quality, safety, identity, purity and potency.

Specification can be defined as the procedure that has been set for assessing the integrity of a drug. Specifications are not only established to ensure product quality, but also to detect and identify any form of deviation or impurities that maybe present in the product. Therefore, set specifications should stand as a method of reference for differentiating a good or inferior material.

The raw materials are taken to the dispensary where the ingredient are weighted according to standard weight as specified by the Production Manufacturer Report (PMR)

Mixing: From the dispensary, the ingredients are transferred to the granulation stage from where it is mixed according to different weight, as indicated above, with various machine carrying out the mixing under different temperature.

Method of mixing: Pour Paracetamol powder inside the mixer, add $12 \mathrm{~kg}$ of corn starch and keep the rest for pasting. Paste is being prepared in paste room by switching the paste pot on, add 2litres of water and when it evaporates, add the remaining $10 \mathrm{~kg}$ of corn starch, $7.5 \mathrm{~kg}$ of galatin and dissolve with $0.93 \mathrm{~kg}$ of propyl and methyl inside the water mixed starch. Back to the mixer, add the already made paste and leave to mix for about 35 minutes.

Drying process: The mixed product will be packed in the bed fluid dryer for the first drying process for 35 minutes, then start mailing on the mailing machine. It is then returned into the fluid dryer for the second drying process, after which $5.155 \mathrm{~kg}$ talc powder and magnesium stearate is added and then keep up for final drying. It should be noted that the drying process should be monitored from time to time.

Laboratory: The micro and chemical laboratory takes sample for approval from where the mixture is either, rejected, passed for rework or moved down to tabulating stage for compression into tablets form. The tablets sample is taken to the laboratory for examination and approval before packaging from where the finished products are passed to the marketing department for sale.

Tableting: This is the stage in which the mixture is compressed into tablets form, at this stage, the machine is adjusted to ensure that it is stable and capable of operating such that virtually all the tablets conform to specifications.

The specifications are given by:

Average Weight $\quad 635.0 \mathrm{mg}$ to $645.0 \mathrm{mg}$

Disintegration Time Less than $15 \mathrm{mins}$

Hardness $\quad 4.0 \mathrm{~kg} / \mathrm{cm}^{2}$ to $7.0 \mathrm{~kg} / \mathrm{cm}^{2}$

Friability Not more than $1.0 \%$

\section{METHOD OF ANALYSIS \\ HISTOGRAM}

A histogram is an accurate representation of the distribution of numerical data. It is an estimate of the probability distribution of a continuous variable and was first introduced by Karl Pearson (Pearson, 1895). The word histogram comes from the Greek histos, meaning pole or mast, and gram, which means chart or graph. Hence, the direct definition of "histogram" is "pole chart". These graphical representations often convey the distribution of the data, and an understanding of the distribution is often important to the statistician.

Also, we use the methods as a means of comparing sample information among different sample sizes and a second class of measure for a frequency distribution describes the characteristics associated with the dispersion (spread).

Central Tendency: These characteristics indicate the amount of spread in the data 
Dispersion: These characteristics indicate the amount of

Skewness of Shape: This indicates the amount of distortion in a symmetrical curve. A symmetrical curve has the same shape to the left and the right of the center line. If the histogram is symmetrical, the skewness is Zero. If the left hand tail is longer, skewness will be negative. If the right hand tail is longer, skewness will be positive.

Kurtosis: Describes the peak in a distribution. A higher kurtosis value means a higher peak of reactive frequency. There are three main characteristics of Kurtosis, they are:

Platykurtic: The distribution is broad and flat

Leptokurtic: Has a slender and high peak

Mesokurtic:Has a slender and high peak.

Interpretation of pattern of Histogram

Center of a distribution

Processes have a target value, the value that the process should be producing, where most output of the process should fall. The center of the distribution in a histogram should in most cases fall on or near the target value. If it does not, the process will need to be adjusted so that the center will hit the target value

\section{CONTROL CHART}

Shewhart control chart was developed in the early 1920's by Walter A. Shewhart of the Bell Telephone Laboratories. To understand the statistical concepts that form the basis of SPC, it is imperative that we must first describe Shewhart's theory of variability.

The control chart is one of the seven tools for quality control (Nancy, 2004). In any production process/, regardless of how well designed or carefully maintained it is, a certain amount of inherent or natural variability will always exist. This natural variability or "background noise" is the cumulative effect of many small essentially unavoidable causes. In the framework of statistical quality control, this natural variability is often called a "stable system of chance causes." A process that is operating with only chance causes of variation present is said to be in statistical control. In other words, the chance causes are an inherent part of the process. Other kinds of variability may occasionally be present in the output of a process. This variability in key quality characteristics usually arises from three sources: improperly adjusted or controlled machines, operator errors, or defective raw materials. We refer to these sources of variability that are not part of the chance cause pattern as assignable causes of variation. A process that is operating in the presence of assignable causes is said to be an out-of-control process.

Processes will often operate in the in-control state for relatively long periods of time. However, no process is truly stable forever, and, eventually assignable causes will occur, seemingly at random, resulting in a shift to an out-of-control state where a large proportion of the process output does not conform to requirements.

In general, control chart is a graphical display of quality characteristics that has been measured or computed from a sample versus the sample number or time. The chart contains a center line that represents the average value of the quality characteristics corresponding to the in-state control. Two other horizontal lines called, the Upper Control Limit (UCL) and the Lower Control Limit (LCL), are also shown on the chart. These control limits are chosen so that if a process is in control, nearly all of the sample points will fall between them.

As long as the points plot within the control limits, the process is said to be in control, and no action is necessary. However, a point that plots outside of the control limit is interpreted as evidence that the process is out of control, and further investigation and corrective action are required to find and eliminate the assignable cause responsible for this. It is important to connect the sample points to the control chart with straight line segment, so that it is easier to visualize how the sequence of points has evolved over time. Even if all the points are plot outside the control limits, if it behaves in a systematic or non-random manner, then this could be an indication that the process is out of control.

Finally, it is worthy to remember that the eventual goal of statistical process control is the elimination of variability in the process. It may not be possible to completely eliminate variability, but the control chart is an

\section{X-Bar Control Chart}

This is a type of chart that show variation in central location and the average of samples. The limits are usually $3 \sigma$ and this can be computed as follows:

$$
\begin{gathered}
U C L=\bar{x}+A_{2} \bar{R} \\
C L=\overline{\bar{x}} \\
L C L=\bar{x}-A_{2} \bar{R}
\end{gathered}
$$

\section{R Control Chart}

This chart is constructed for the variation in the dispersion or spread of the product.

$$
\begin{aligned}
U C L & =\bar{R} D_{4} \\
C L & =\bar{R} \\
L C L & =\bar{R} D_{3}
\end{aligned}
$$




\section{RUNS TEST (TEST FOR RANDOMNESS)}

A run is a succession of items of the same class. When the output of a process, for example is classified as defective and non-defective, a succession of defective units would be a "run" of this class units. If the plotted points in the charts falls within the upper and lower control limits, there is need to test for randomness so as to ascertain if the process is actually in statistical control.

We can define "A" to be a point that fall above the central line and "B" a point that falls below the "CL" on the chart, if we observe the sequence of occurrence of these points, we can form runs.

The hypothesis for testing of randomness is as follows:

$\mathrm{H}_{\mathrm{o}}$ : The process is random VS

$\mathrm{H}_{1}$ : The process is not random

Decision Rule: Reject $\mathrm{H}_{\mathrm{o}}$ if $p<\alpha$ at $\alpha=0.05$, otherwise, do not reject $\mathrm{H}_{\mathrm{o}}$.

To obtain " $p$ " the following calculations are done

Test Statistics

$$
Z=\frac{r-\mu_{r}}{\delta_{r}} \sim N(0,1)
$$

Where,

$$
\begin{aligned}
& \mu_{r}=\frac{2 n_{A} n_{B}}{n_{A}+n_{B}}+1 \\
& \delta_{r}=\sqrt{\frac{2 n_{A} n_{B}\left(2 n_{A} n_{B}-n_{A}-n_{B}\right)}{\left(n_{A}+n_{B}\right)^{2}\left(n_{A}+n_{B}-1\right)}} \\
& Z_{r}=\frac{r-\mu}{\delta_{r}} \\
& P=\operatorname{Pr}\left(Z \geq Z_{r}\right) \\
& \text { Where } r \text { is the number of runs, } \\
& n_{A} \text { is the number of A and } \\
& n_{B} \text { is the number of B }
\end{aligned}
$$

\section{Process Capability Indices:}

The process capability index $\left(C_{p}\right.$ and $\left.C_{p k}\right)$ are obtained using the formula $C_{p}=\frac{U S L-L S L}{6 \sigma}$ Where, USL and LSL are the specification limits and $6 \sigma$ is $99.73 \%$ process capability.

$C_{p k}=\min \left[\frac{U S L-\mu}{3 \sigma}, \frac{\mu-L S L}{3 \sigma}\right]$ Where, $\mu$ is the mean of the sample group and $3 \sigma$ is the one-sided process capability.

The correlation coefficient is given as,

$$
r=\frac{\sum_{i=1}^{n} x y-n \bar{x} \bar{y}}{\sqrt{\left(\sum_{i=1}^{n} x_{i}^{2}-n \bar{x}^{2}\right)} \sqrt{\left(\sum_{i=1}^{n} y_{i}^{2}-n \bar{y}^{2}\right)}}
$$

Where $\mathrm{x}$ and $\mathrm{y}$ are the quality characteristics being considered

To test the significance of the correlation between the quality characteristics, we set up the null hypothesis.

$H_{o}: p=0$ i.e. there is no significance in their association.

$\mathrm{Vs}$

$H_{1}:$ Not $H_{0}$

Test Statistic:

$t=\frac{r \sqrt{n-2}}{\sqrt{1-r^{2}}}, t_{n-2, \frac{\alpha}{2}}$

Where, $r$ is the correlation coefficient

And $n$ is the sample size

Decision Rule: reject $H_{0}$ if $p<\alpha$ at $\alpha=0.05$, otherwise do not reject $H_{0}$

\section{ANALYSIS AND RESULTS}

Distribution pattern of the quality characteristics is studied and monitored using histogram and control charts respectively. The process capability of each of the characteristics is also assessed. The data used for the computational analysis is located in the appendix.

\section{ANALYSIS ON AVERAGE WEIGHTS}

Weight is one of the characteristics being studied in this paper. The average weights of all daily products are 
being obtained, 5 samples are being taken and the average weight is what we used in this paper. The histogram of the average weight is given below;

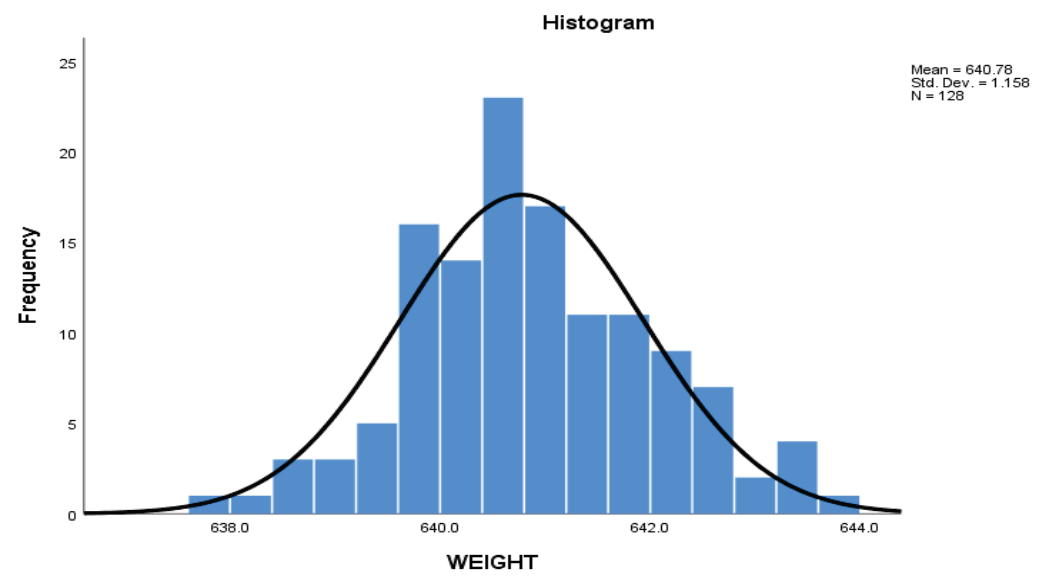

fig 1a: Histogram on average Weight

From fig la above, the histogram is close to being symmetric and uni-modal, which shows that the distribution pattern is approximately normal.

\section{Monitoring Average Weight}

In order to monitor the weight, $\bar{X}$ chart and Range-Chart are used i.e. to keep a check on the average quality of Paracetamol (Tumol $\times 200$ ) tablet with respect to the weight of the tablet, $\bar{X}$-Chart is plotted and the control limits are estimated. The result of the analysis is given below;

$\bar{X}=640.777=\mathrm{CL}$

\section{$\bar{X}$-Chart}

$$
\begin{aligned}
& \mathrm{UCL}=\overline{\bar{X}}+A_{2} * \bar{R}==644.251 \\
& \mathrm{LCL}=\overline{\bar{X}}-A_{2} * \bar{R}==637.302 \\
& \text { R-Chart } \\
& \bar{R}=4.281=\mathrm{CL} \\
& \mathrm{UCL}=D_{4} \bar{R}=9.054 \\
& \mathrm{LCL}=D_{3} \bar{R}=0.000
\end{aligned}
$$

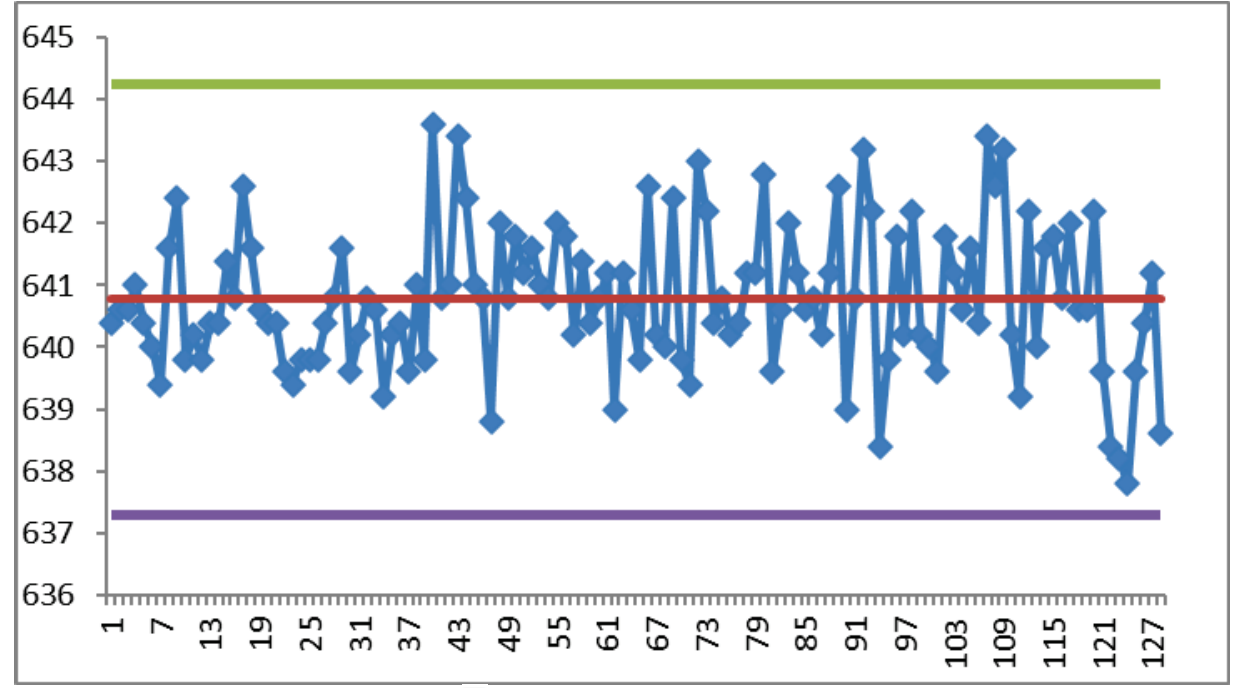

$\mathrm{UCL}=644.251$ 


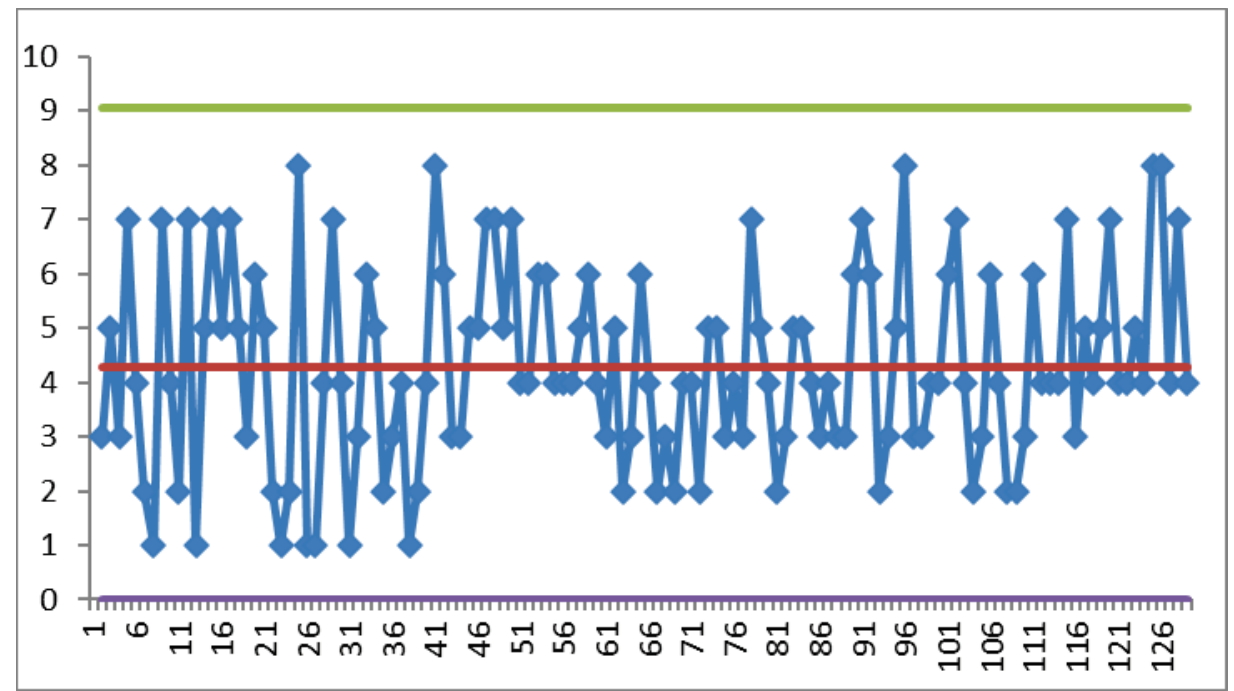

$\mathrm{UCL}=9.055$

fig 1c: R-Chart on Average Weight

From fig $1 \mathrm{~b}$ and fig $1 \mathrm{c}, \bar{X}$ chart indicates that weight is In-control, and the R-Chart also indicates the weight is in control. We can therefore generalize that weight is in statistical control for the specification limit given.

Process Capability Analysis

$$
\begin{aligned}
\mathbf{U S L}=645 \\
\mathbf{L S L}=635 \\
C_{p}=\frac{U S L-L S L}{6 \tau}=\frac{645-635}{6 * 1.158}=1.439 \\
C_{p k}=\min \left[\frac{U S L-\mu}{3 \sigma}, \frac{\mu-L S L}{3 \sigma}\right] \\
C_{p k}=\min \left[\frac{645-640.777}{3 * 1.158}, \frac{640.777-635}{3 * 1.158}\right] \\
C_{p k}=\min [1.216, \quad 1.663] \\
C_{p k}=1.216
\end{aligned}
$$

Since $C_{p}=1.439>1$ and $C_{p k}=1.216>1$, we therefore conclude that the average WEIGHTS is capable of producing within its specification limits.

\section{ANALYSIS ON DISINTEGRATION TIME}

\section{Histogram}

Disintegration Time is also an essential quality characteristics being studied in this paper. The disintegration Time of Paracetamol (Tumol $\times 200$ ) is the time it will take the tablet to dissolve in the human body after being ingested. The time specification is a maximum of 15 minutes. Histogram was used to determine the distribution pattern.

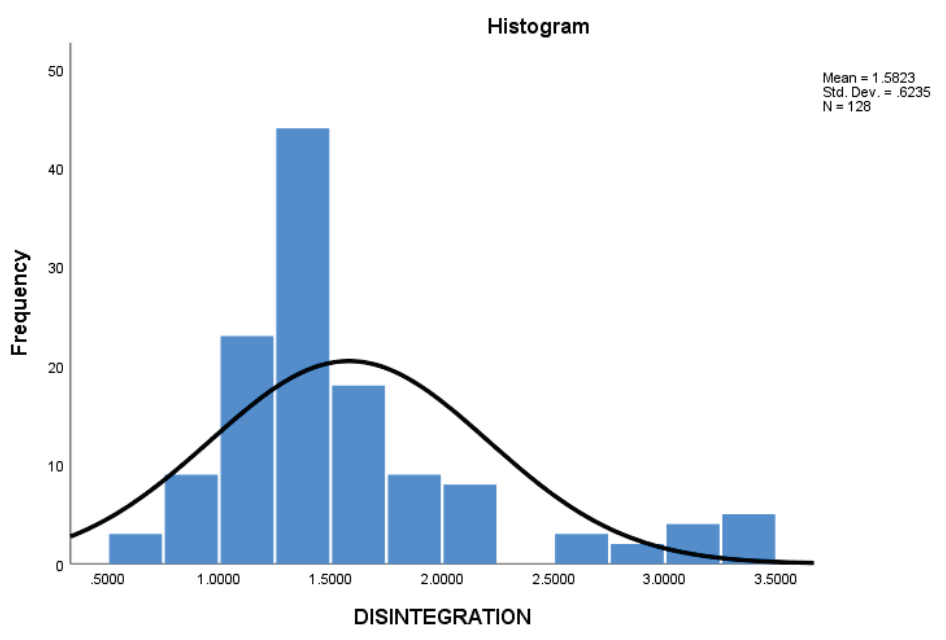

fig 2a: Histogram on Disintegration time

It is observed in fig $2 \mathrm{a}$ above that the histogram is bimodal which shows no recognizable pattern and also doesn't 
reveal much information.

\section{Process Capability Analysis}

$$
\begin{array}{rl}
\mathbf{U S L}=6.0 & \mathbf{L S L}=0.1 \\
C_{p k}=\min \left[\frac{U S L-\mu}{3 \sigma}, \frac{\mu-L S L}{3 \sigma}\right] & \begin{array}{c}
\text { LSL } \\
C_{p}=\frac{U S L}{6 * 0.42 .4}=2.32
\end{array} \\
C_{p k}=\min \left[\frac{6.0-1.59}{3 * 0.424}, \frac{1.59-0.1}{3 * 0.424}\right] & \\
C_{p k}=\min [3.47,1.17] & C_{p k}=1.17
\end{array}
$$

Since $C_{p}=2.32>1$ and $C_{p k}=1.17>1$, we therefore conclude that the Disintegration Time is capable of producing within its specification limits.

\section{ANALYSIS ON FRIABILITY}

\section{Histogram}

Friability is also one of the quality characteristics being studied in this paper. The histogram of the friability is given below;

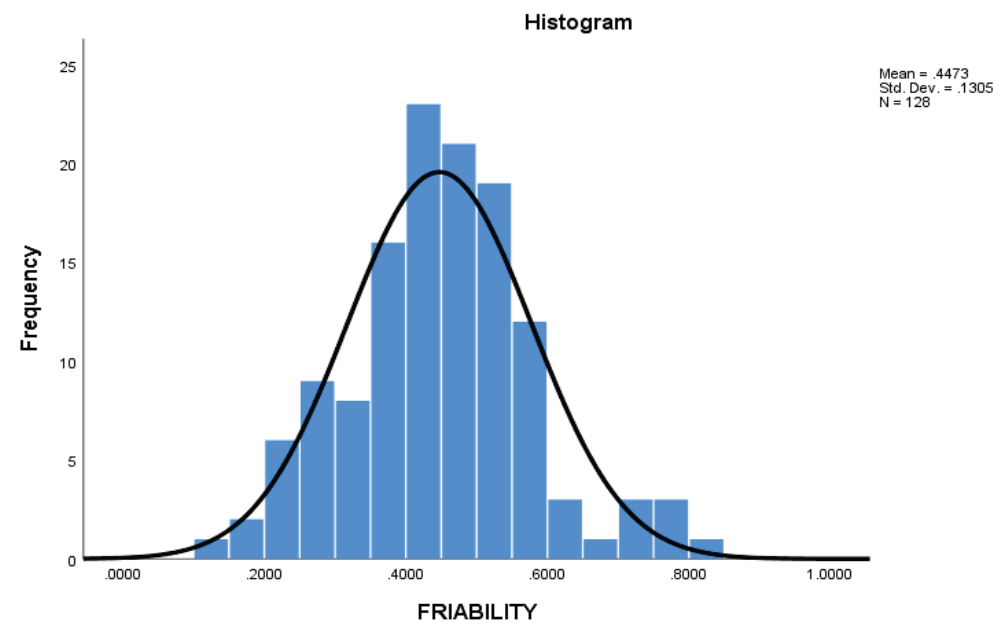

fig 3a: Histogram on Friability

It is observed in fig $3 \mathrm{a}$ above that the histogram is symmetric and bi-modal, which shows that the distribution pattern is approximately normal.

\section{ANALYSIS ON HARDNESS}

Histogram

Hardness is also an essential quality characteristics being studied in this paper. The histogram of the hardness is given below; 


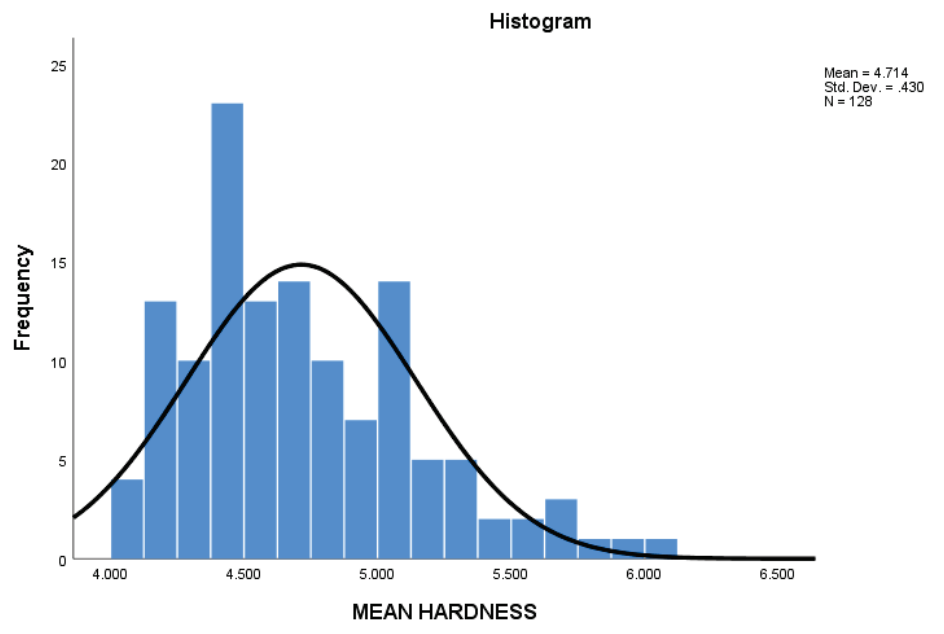

fig 4a: Histogram on Hardness

It is observed in fig $4 \mathrm{a}$ above that the histogram isuni-modal, which shows that the distribution pattern is approximately normal

\section{COMPUTATION OF ASSOCIATION BETWEEN PAIRS OF QUALITY CHARATERISTICS \\ Hypothesis Testing}

$H_{0}: p=0$ i.e. there is no significance in their association

$H_{1}$ : Not $H_{0}$

Decision rule: Reject $H_{0}$ if $p<\alpha=0.05$, otherwise do not reject $H_{0}$

Test statistics:

$t=\sqrt[r]{\left[\frac{n-2}{1-r^{2}}\right]} \sim t_{n-2,1}-\frac{\alpha}{2}$

\section{Correlations}

\begin{tabular}{|c|c|c|c|c|c|}
\hline & & Disintegration & Hardness & Friability & Weight \\
\hline \multirow{3}{*}{ Disintegration } & Pearson Correlation & 1 & .147 & .008 & .081 \\
\hline & Sig. (2-tailed) & & .097 & .924 & .365 \\
\hline & $\mathrm{N}$ & 128 & 128 & 128 & 128 \\
\hline \multirow{3}{*}{ Hardness } & Pearson Correlation & .147 & 1 & .114 & .050 \\
\hline & Sig. (2-tailed) & .097 & & .201 & .574 \\
\hline & $\mathrm{N}$ & 128 & 128 & 128 & 128 \\
\hline \multirow{3}{*}{ Friability } & Pearson Correlation & .008 & .114 & 1 & .173 \\
\hline & Sig. (2-tailed) & .924 & .201 & & .051 \\
\hline & $\mathrm{N}$ & 128 & 128 & 128 & 128 \\
\hline \multirow{3}{*}{ Weight } & Pearson Correlation & .081 & .050 & .173 & 1 \\
\hline & Sig. (2-tailed) & .365 & .574 & .051 & \\
\hline & $\mathrm{N}$ & 128 & 128 & 128 & 128 \\
\hline
\end{tabular}

\section{fig5: Correlation between Pairs of Quality Characteristics}

The correlation analysis carried out in fig 5 above shows a significant association for all pairs of variables.

\section{SUMMARY OF RESULTS}

The histogram in fig 1a, 2a, 3a and 4a shows that the underlining distribution Weight, Disintegration Time, Friability and Hardness are approximately normally distributed.

The quality characteristics when monitored using $\bar{X}$ - Chart and R-Chart as in fig. $1 \mathrm{~b}$ and 1c were plotted within the control limits. When tested for randomness using Runs Test, it was confirmed that all the quality characteristics are in statistical control.

The capability indices $\left(C_{p}\right.$ and $\left.C_{p k}\right)$ when computed have values greater than one indicating that they are well centered and capable.

Also, the correlations in fig. 5 confirm linear relationship between all pairs of quality characteristics. 


\section{CONCLUSION}

All the quality characteristics studied are in statistical control, are capable of producing within their respective specification limits and all pairs of the quality characteristics are significantly correlated.

\section{REFERENCES}

Douglas C. Montgomery (2009). Introduction to Statistical Quality Control sixth edition, Arizona state University.

Keith M. Bower. Process Capability Analysis using MINITAB(1)

LalmohanBhar (2012).Nonparametric Test, Library Avenue, New Delhi

Robert B. Davis (2004). Constructing Control Charts with Average Run Length Constraints (session 1465), Miami University.

Stevens (1999). Significance test of Correlation, EDPSY 604

S.C. Gupta. Fundamentals of Statistics Sixth Edition 